\title{
The Transient Method and Experimental Study on Threshold Pressure Gradient of Heavy Oil in Porous Media
}

\author{
Z.X. Pang*,1 and H.Q. Liu ${ }^{2}$ \\ ${ }^{1}$ MOE Key Laboratory of Petroleum Engineering, Beijing 102249, China; ${ }^{2}$ Faculty of Petroleum Engineering, China \\ University of Petroleum, Beijing 102249, China
}

\begin{abstract}
On the basis of flow characteristics and material balance principle, a one-dimensional theoretical model of heavy-oil migration in porous media was established. The model considered micro-compressible property and nonNewtonian behavior of heavy oil. A new method, the transient method, was introduced to calculate the threshold pressure gradient in porous media. The method was designed to measure the inlet pressure of porous media during experiments. Finally, the threshold pressure gradient was worked out according to the mathematical model. The threshold pressure gradient of heavy oil was more accurate by the transient method than the steady state method. The threshold pressure gradients of three oil samples in different permeable porous media were measured according to the transient method. The experimental results showed that heavy oil migration was influenced by petroleum composition and pore structure of porous media. The threshold pressure gradient gradually decreased as temperature and permeability increased in porous media.
\end{abstract}

Keywords: Heavy oil, Threshold pressure gradient, Transient method, Porous media, Inflection temperature.

\section{INTRODUCTION}

Heavy oil and bitumen were important hydrocarbon resources that played an increasingly great role in petroleum supply for the world [1-3]. The total amount of the heavy oil resources all over the world were 10 trillion barrels, nearly three times of the conventional oil in the world. Heavy oils could not be recovered by traditional ways due to their high viscosity and apparent flow resistance in oil reservoirs. Thermal oil recovery methods have been the most effective enhanced oil recovery technologies to recover heavy oil [4]. Thermal methods aimed at reducing oil viscosity to increase its mobility, which mainly included in-situ combustion, steam drive, cyclic steam stimulation and steam assisted gravity drainage.

Heavy oils were complex fluids that could cause a variety of difficulties during production, separation, transportation and refining [5,6]. Heavy oil always posed a great challenge to production and transportation systems due to its high viscosity. Meanwhile, viscosity was related to API gravity, solution gas oil ratio, pressure and temperature. Many researchers explained that heavy oil viscosity usually varied dramatically during various production processes, such as a thermal or solvent injection processes [7-10].

Luo and $\mathrm{Gu}$ (2007) [11] carried out many experiments to study thermal flow properties of heavy oil. The results focused on the relationships between the compositions of heavy oils, in particular asphaltine contents, and their flow

*Address correspondence to this author at the MOE Key Laboratory of Petroleum Engineering, Beijing 102249, China; Tel: 010-89731163; Fax: 010-89733511; E-mail: pxiad9827@163.com properties. Some researchers observed that as temperature decreases, not only the viscosity increased but also the rheological behavior of heavy oils became non Newtonian [12-14]. The heavy oil exhibited non-Newtonian flow behavior of shear thinning, which could be best presented by the power law model $[15,5]$.

Generally, heavy oil contained high contents of large molecular hydrocarbon and asphaltenes but only a small amount of light hydrocarbons and easily volatile components $[4,7,11,13]$. Therefore, heavy oil was a kind of high viscosity and large density of fluid, which difficultly flowed in porous media under natural conditions. The results from experiments and oil-field applications showed that the seepage of heavy oil was presented nonlinear in porous media $[16,17]$. Heavy oil could be driven in porous media until pressure difference was more than a critical value that was called threshold pressure. The steady-state method was very difficult to accurately control flow rate of heavy oil and perfectly measured pressure difference, especially, at lower flow rate [18-21]. Meanwhile, the steady-state method needed to carry out many experiments at different flow rates.

In this article, according to seepage characteristics of heavy oil and mass balance theory, a transient method was presented to measure threshold pressure gradient of heavy oil in porous media. This method only needed to monitor pressure variation rather than flow rate of heavy oil in sandpack. Therefore, it was superior to the steady-state method.

\section{THEORY}

\subsection{Mathematic Model}

Generally, heavy oil reservoirs presented some characteristics, such as loose sand grains, high permeability 
and large porosity [1]. A long sand-pack filled with uniform quartz grains or glass beads was employed to measure threshold pressure gradient of heavy oil in porous media. A transient model was established on the basis of unsteady seepage theory and material balance principle. The following basic assumptions were presented: (1) Porous media was incompressible and homogeneity; (2) Temperature was same in porous media; (3) Crude oil was slightly compressible. Therefore, the following equations could be established.

(1) Motion equation

$$
\left\{\begin{array}{lr}
\vec{v}=-\frac{K}{\mu_{\mathrm{o}}}(\operatorname{grad} p+\lambda) & |\operatorname{grad} p|>\lambda \\
\vec{v}=0 & |\operatorname{grad} p| \leq \lambda
\end{array}\right.
$$

(2) Conservation equation

$$
\frac{\partial\left(\rho_{\mathrm{o}} \phi\right)}{\partial t}+\frac{\partial\left(\rho_{\mathrm{o}} \vec{v}\right)}{\partial x}=0
$$

\section{(3) Equation of state}

Density of heavy oil under pressure, $p$, was:

$$
\rho_{\mathrm{o}}=\rho_{\mathrm{osc}} e^{c_{\mathrm{o}}\left(p-p_{\mathrm{sc}}\right)}
$$

(4) Boundary and initial conditions

$\left.p\right|_{x=L}=p_{s c}$, corresponding to the outlet pressure of sand pack.

$\left.\frac{\partial p}{\partial x}\right|_{x=0}=-\lambda$, corresponding to shutting in the inlet of sand pack, that is, no flow at the inlet.

$\left.p\right|_{t=0}=p_{i}$, corresponding to the initial pressure of sand pack.

\subsection{Solution Method}

(1) Simplified equation

$$
\begin{aligned}
& \frac{\partial\left(\rho_{\mathrm{o}} \vec{v}\right)}{\partial x}=-\frac{K \rho_{\mathrm{osc}}}{\mu_{\mathrm{o}}}\left\{\frac{1}{c_{\mathrm{o}}} \frac{\partial^{2}\left[e^{c_{\mathrm{o}}\left(p-p_{s c}\right)}\right]}{\partial x^{2}}+\lambda \frac{\partial\left[e^{c_{\mathrm{o}}\left(p-p_{s c}\right)}\right]}{\partial x}\right\} \\
& \text { If } \bar{p}=e^{c_{\mathrm{o}}\left(p-p_{s c}\right)}, \text { then } \\
& \left\{\begin{array}{l}
\frac{\partial^{2} \bar{p}}{\partial x^{2}}+c_{\mathrm{o}} \lambda \frac{\partial \bar{p}}{\partial x}=\frac{c_{\mathrm{o}} \phi \mu_{\mathrm{o}}}{K} \frac{\partial \bar{p}}{\partial t} \\
\left.\bar{p}\right|_{t=0}=e^{c_{\mathrm{o}}\left(p_{\mathrm{i}}-p_{\mathrm{sc}}\right)}=\left.\frac{\bar{p}}{\bar{p}}\right|_{x=L}=1 \\
\left.\frac{1}{\bar{p}} \frac{\partial \bar{p}}{\partial x}\right|_{x=0}=-c_{\mathrm{o}} \lambda
\end{array}\right.
\end{aligned}
$$

(2) Dimensionless equation

$$
\text { If } p_{D}=\bar{p}, X_{D}=\frac{x}{L}, t_{D}=\frac{K}{\phi \mu_{\mathrm{o}} c_{\mathrm{o}} L^{2}} t, \lambda_{D}=L c_{\mathrm{o}} \lambda \text {, then }
$$

$\left\{\begin{array}{l}\frac{\partial^{2} p_{D}}{\partial x_{D}^{2}}+\lambda_{D} \frac{\partial p_{D}}{\partial x_{D}}=\frac{\partial p_{D}}{\partial t_{D}} \\ \left.p_{D}\right|_{t_{D}=0}=\overline{p_{\mathrm{i}}} \\ \left.p_{D}\right|_{x_{D}=1}=1 \\ \left.\frac{1}{p_{D}} \frac{\partial p_{D}}{\partial x_{D}}\right|_{x_{D}=0}=-\lambda_{D}\end{array}\right.$

(3) Solution of equations

In order to obtain the solution, we assumed that

$p_{D}\left(x_{D}, t_{D}\right)=u\left(x_{D}, t_{D}\right)+w\left(x_{D}\right)$

Therefore,

$$
\left\{\begin{array}{l}
\frac{\partial^{2} u}{\partial x_{D}^{2}}+\lambda_{D} \frac{\partial u}{\partial x_{D}}+\frac{d^{2} w}{d x_{D}^{2}}+\lambda_{D} \frac{d w}{d x_{D}}=\frac{\partial u}{\partial t_{D}} \\
\left.u\right|_{t_{D}=0}=\bar{p}_{\mathrm{i}}-w\left(x_{D}\right) \\
\left.u\right|_{x_{D}=1}=1-w(1) \\
\left.\left(\frac{\partial u}{\partial x_{D}}+\lambda_{D} u\right)\right|_{x_{D}=0}=-\left.\left(\frac{d w}{d x_{D}}+\lambda_{D} w\right)\right|_{x_{D}=0}
\end{array}\right.
$$

If we assumed that $w\left(x_{D}\right)$ was satisfied with the ordinary differential equations as following:

$\left\{\begin{array}{l}\frac{d^{2} w}{d x_{D}{ }^{2}}+\lambda_{D} \frac{d w}{d x_{D}}=0 \\ w(1)=1 \\ \left.\left(\frac{d w}{d x_{D}}+\lambda_{D} w\right)\right|_{x_{D}=0}=0\end{array}\right.$

We could derive the following solution:

$w\left(x_{D}\right)=e^{\lambda_{D}\left(1-x_{D}\right)}$

Therefore, the equation (8) could be simplified to

$\left\{\begin{array}{l}\frac{\partial^{2} u}{\partial x_{D}^{2}}+\lambda_{D} \frac{\partial u}{\partial x_{D}}=\frac{\partial u}{\partial t_{D}} \\ \left.u\right|_{t_{D}=0}=\overline{p_{\mathrm{i}}}-e^{\lambda_{D}\left(1-x_{D}\right)} \\ \left.u\right|_{x_{D}=1}=0 \\ \left.\left(\frac{\partial u}{\partial x_{D}}+\lambda_{D} u\right)\right|_{x_{D}=0}=0\end{array}\right.$

Let $u\left(x_{D}, t_{D}\right)=e^{-\frac{\lambda_{D}}{2} x_{D}} e^{c_{0} t_{D}} v\left(x_{D}, t_{D}\right)$ and $C_{0}=-\frac{\lambda_{D}{ }^{2}}{4}$, then

$\left\{\begin{array}{l}\frac{\partial^{2} v}{\partial x_{D}^{2}}=\frac{\partial v}{\partial t_{D}} \\ \left.v\right|_{t_{D}=0}=e^{\frac{\lambda_{D}}{2} x_{D}}\left[\overline{p_{\mathrm{i}}}-w\left(x_{D}\right)\right]=F\left(x_{D}\right) \\ \left.v\right|_{x_{D}=1}=0 \\ \left(\frac{\partial v}{\partial x_{D}}+\frac{\lambda_{D}}{2} v\right)_{x_{D}=0}=0\end{array}\right.$ 
If equation (12) was solved according to separation of variable by superposition, we could derive

$\beta_{m} \operatorname{ctg}\left(\beta_{m}\right)=\frac{\lambda_{D}}{2}$

If we used Normalization factor of $N=\int_{0}^{1} \sin ^{2} \beta_{m}(1-x) d x$, then

$\frac{1}{N\left(\beta_{m}\right)}=\frac{8 \beta_{m}{ }^{2}+2 \lambda_{D}{ }^{2}}{4{\beta_{m}}^{2}+\lambda_{D}{ }^{2}-2 \lambda_{D}}$

The expression of $p_{D}$ was worked out from the equations of (6), (11) and (12).

$p_{D}=e^{-\frac{\lambda_{D}}{2} x_{D}} e^{-\frac{\lambda_{D}^{2} t_{D}}{4}}\left[\sum_{m=1}^{\infty} e^{-\beta_{m}^{2} t_{D}} \frac{X\left(\beta_{m}, x_{D}\right)}{N\left(\beta_{m}\right)} \int_{0}^{1} X\left(\beta_{m}, x_{D}\right) F\left(x_{D}\right) \mathrm{d} x_{D}\right]+e^{\lambda_{D}\left(1-x_{D}\right)}$

Where, $X_{m}=\sin \left[\beta_{m}\left(1-x_{D}\right)\right]$;

$F\left(x_{D}\right)=e^{\frac{\lambda_{D}}{2} x_{D}}\left[1-e^{\lambda_{D}\left(1-x_{D}\right)}\right]$.

\section{EXPERIMENTS}

\subsection{Experimental Apparatus}

The flow experiments of heavy oil in porous media were carried out using a sand-pack flooding unit, which included constant flow pump, heavy oil tank, sand-pack, constant temperature oven, pressure transducer, temperature sensor, pressure gauge, data acquisition systems and computer. A schematic of the unit was shown in Fig. (1). The sand-pack was $60 \mathrm{~cm}$ long with $3.8 \mathrm{~cm}$ in inner diameter, in which was filled with unconsolidated quartz grains. The sand-pack was equipped with three pressure transducers and three temperature sensors. In order to prevent heavy oil from plugging pipelines, one small buffer container, which was a small hollow tank, was installed between pressure tap and pressure transducer. Heavy oil in oil tank was injected into sand-pack by a constant flow bump. Heavy oil tank, sandpack, small buffer containers and temperature sensors were all equipped in the constant temperature oven. The data of temperatures and pressures were transferred to a computer by the data acquisition systems.

\subsection{Experimental Procedure}

(1) The sand-pack filled with quartz grains was first equipped in the constant temperature oven. Then the oven and the oil tank were controlled to ( in) a certain temperature over 2 hours.

(2) Heavy oil was injected into sand-pack until the flow rate of heavy oil was steady in the outlet of sand-pack.

(3) The valve of the outlet was shut in but heavy oil was still injected into sand-pack by the constant flow bump until the inlet pressure was $0.5 \mathrm{MPa}$ higher than reservoir original pressure. Then the valve of the inlet was shut in.

(4) The temperature of the oven was evaluated about 10 ${ }^{\circ} \mathrm{C}$ in order to accelerate the pressure balance of heavy oil in sand-pack.

(5) When the pressures were wholly equal to each other from the inlet to the outlet of sand-pack, the valve of the outlet was opened. Simultaneously, the inlet pressure of sand-pack was continuously recorded until the inlet pressure was steady.

(6) The dimensionless pressure of the inlet at a certain temperature could be calculated according to the equation (15). At last the threshold pressure gradient was calculated resulting from experimental results.

\subsection{Validation of Transient Method}

A heavy oil sample was employed to measure its threshold pressure gradient in sand-pack respectively at 30

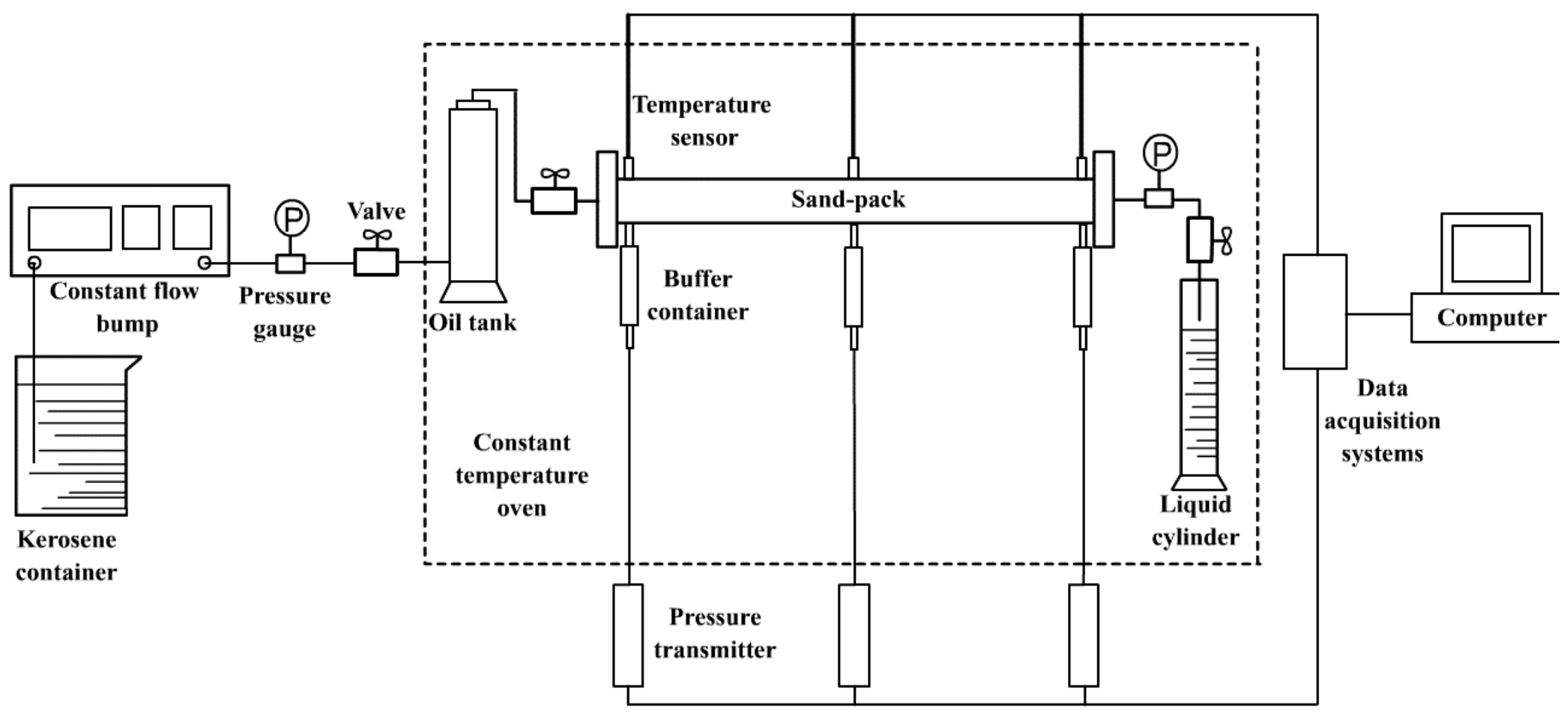

Fig. (1). The Schematic of heavy oil threshold pressure gradient experiment. 
and $50{ }^{\circ} \mathrm{C}$. Firstly, a series of experiments were carried out to establish the relationships between pressure gradient and flow rate of heavy oil in porous media at steady state. The threshold pressure gradient of this oil sample was calculated when flow rate was equal to zero according to the experimental results. The experimental parameters were listed in Table 1. The permeability of sand-pack was 2.55 $\mu \mathrm{m}^{2}$, which was measured according to Darcy's Law. The porosity of sand-pack was 0.37 .

Table 1. The Parameters of Porous Media and Oil Properties

\begin{tabular}{|c|c|c|c|}
\hline & Parameters & \multicolumn{2}{|c|}{ Value } \\
\hline \multirow{2}{*}{ Sand-pack } & Length (cm) & \multicolumn{2}{|c|}{60.0} \\
\hline & Diameter $(\mathrm{cm})$ & \multicolumn{2}{|c|}{3.8} \\
\hline \multirow{3}{*}{ Porous media } & Quartz grain & \multicolumn{2}{|c|}{160 meshes } \\
\hline & Porosity (\%) & \multicolumn{2}{|c|}{37.0} \\
\hline & Permeability $\left(\mu \mathrm{m}^{2}\right)$ & \multicolumn{2}{|c|}{2.55} \\
\hline \multirow{4}{*}{ Heavy oil } & Compressibility (1/MPa) & \multicolumn{2}{|c|}{$4.5 \times 10^{-3}$} \\
\hline & \multirow{3}{*}{$\begin{array}{l}\text { Temperature } \\
\text {-viscosity } \\
\left({ }^{\circ} \mathrm{C}, \mathrm{mPa} \cdot \mathrm{s}\right)\end{array}$} & 30 & 6110.00 \\
\hline & & 50 & 1401.44 \\
\hline & & 80 & 237.04 \\
\hline
\end{tabular}

The relationships between pressure gradient and flow rate at steady state were shown in Fig. (2). At experimental temperature, pressure gradient was linear with flow rate but the line did not pass through the origin of coordinate axis. It showed that heavy oil began to flow in porous media when displacement pressure difference was larger than threshold pressure difference. Threshold pressure gradient was 0.3583 $\mathrm{MPa} / \mathrm{m}$ at $30{ }^{\circ} \mathrm{C}$ for experimental oil sample. It decreased to be $0.1554 \mathrm{MPa} / \mathrm{m}$ at $50{ }^{\circ} \mathrm{C}$. Therefore, threshold pressure gradient could be decreased to zero when temperature increased to a certain value, that is, heavy oils changed to Newton fluid from visco-plastic fluid at the temperature what was called inflection temperature $[5,9]$.

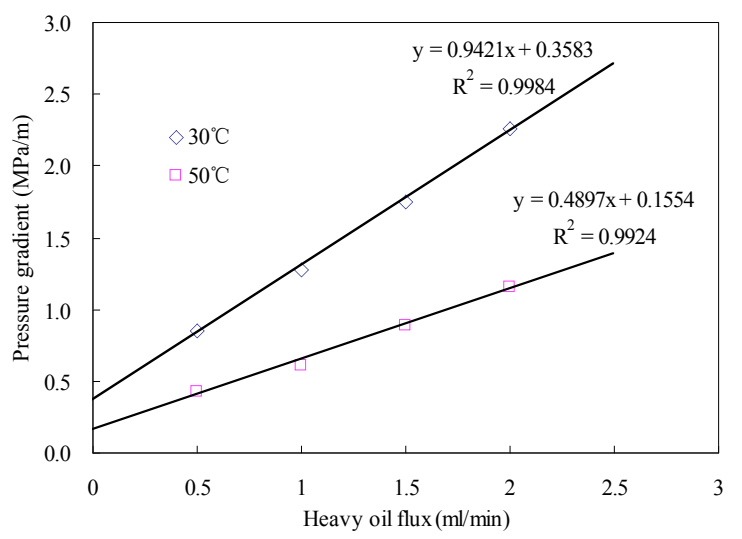

Fig. (2). Threshold pressure gradient vs. heavy oil flux at different temperature.

The results of experiment and calculation were both shown in Fig. (3), which depicted the relationships between dimensionless pressure and dimensionless time at different temperature. The relative errors of threshold pressure gradient were respectively $0.79 \%$ and $2.18 \%$ between steady method and transient method. Therefore, the calculated threshold pressure gradients from transient method were reliable as well as the steady state method. However, the transient method only measured the inlet pressure of sandpack with time after the outlet was opened. Therefore, the transient method need not consider the influence of flow rate on experimental results. Meanwhile, only once experiment was carried out to calculate the threshold pressure gradient of heavy oil. But the steady-state method need measure the relationships between pressure gradients and flow rates, especially, low flow rates of heavy oil in porous media. Therefore, the lower accuracy, which mainly resulted from measuring low flow-rate and small pressure difference, introduced a larger error for threshold pressure gradient in the steady-state method.

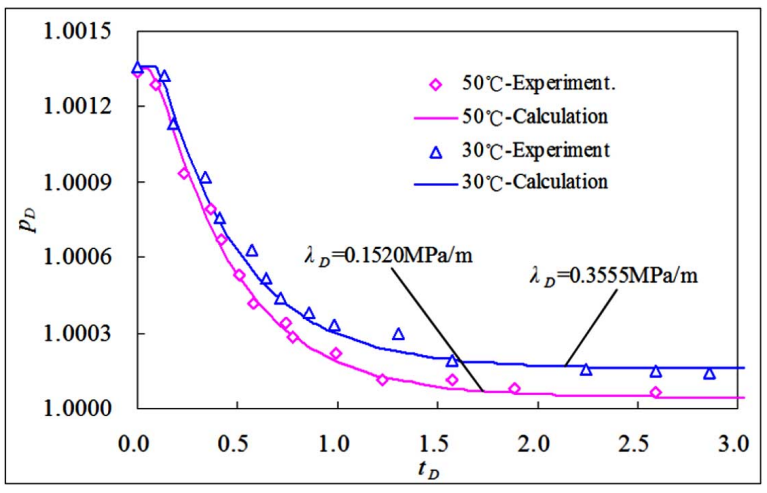

Fig. (3). Comparison of dimensionless pressure between experiments and calculations at different temperature.

\subsection{Calculation Method of Threshold Pressure Gradient}

The basic parameters, such as sand-pack length, sandpack diameter, permeability, porosity, heavy oil viscosity, heavy oil density, isothermal compressibility, and a series of threshold pressure gradients were introduced into the equation (15) to calculated the corresponding curves of dimensionless pressure vs. dimensionless time. Then the equation (16) was employed to calculate the corresponding pressure differences along porous media for different threshold pressure gradients. The value of threshold pressure gradient was constantly adjusted until the calculated pressures were matched to the experimental pressures. Therefore, the adjusted value was the real threshold pressure gradient of this heavy oil.

$\Delta p=\frac{1}{c_{\mathrm{o}}} \operatorname{Ln}\left(p_{D}\right)$

If the basic parameters were utilized from the former experiments at $30^{\circ} \mathrm{C}$, and the values of threshold pressure gradient were respectively chosen $0 \mathrm{MPa} / \mathrm{m}, 0.5 \mathrm{MPa} / \mathrm{m}$, $1 \mathrm{MPa} / \mathrm{m}$, and $1.5 \mathrm{MPa} / \mathrm{m}$, then the curves of pressure differences with dimensionless time could be calculated according to the equations (15) and (16), shown in Fig. (4). It presented the calculated results of the top 100 and the top 200 of the sum expression in the equation (15). The results showed that the lines (the top 100) and the symbols (the top 
200) were completely coincident to each other in Fig. (4). Therefore, the results of top 100 in the equation (15) were wholly satisfied with accuracy.

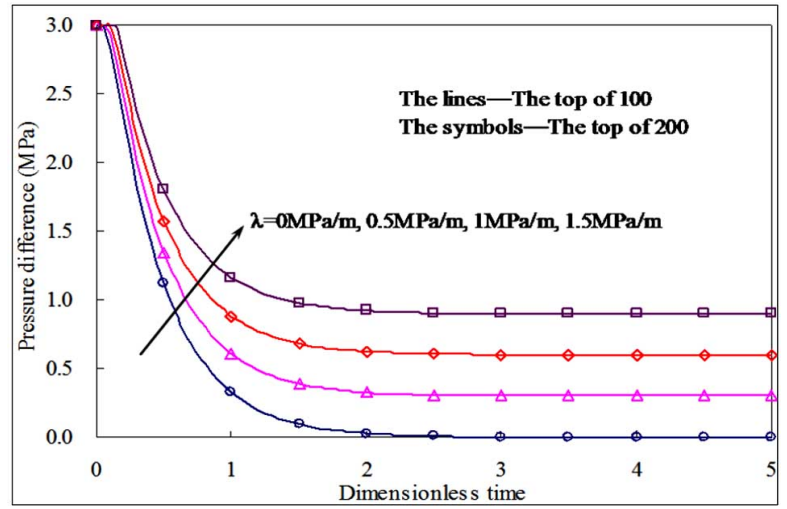

Fig. (4). Comparison of pressure difference between the top of 100 and 200 in equation (9).

\subsection{Prediction of Steady Time}

When dimensionless time was over 4, pressure distribution gradually tended to be steady in Fig. (4). Therefore, data acquisition time in experiments could be calculated from the following equation:

$t=4 \times 1000 \frac{\phi \mu_{0} c_{0} L^{2}}{K}$

According to the basic parameters in the former experiments, such as $\phi=0.37, \mu_{0}=6110 \mathrm{mPa} \cdot \mathrm{s}, c_{\mathrm{o}}=4.5 \times 10^{-}$ ${ }^{3} \mathrm{MPa}^{-1}, L=0.6 \mathrm{~m}, K=2.55 \mu \mathrm{m}^{2}$, the time of steady state was $5434.3 \mathrm{~s}$ according to the equation (17). In other words, the inlet pressure gradually tended to be steady for about 1.5 hours from opening the outlet of sand-pack.

\section{EXPERIMENTAL RESULTS AND DISCUSSION}

In our experiments, three heavy oil samples were utilized to study the relationships between oil viscosity and threshold pressure gradient of heavy oil. The permeability were

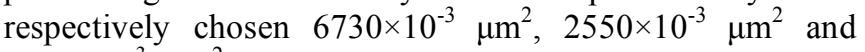
$1600 \times 10^{-3} \mu^{2}$. The viscosity of three heavy oil were respectively chosen $1820 \mathrm{mPa} \cdot \mathrm{s}$ on behalf of low viscosity of ordinary heavy oil, $6110 \mathrm{mPa} \cdot \mathrm{s}$ on behalf of middle viscosity of ordinary heavy oil and $10715 \mathrm{mPa} \cdot \mathrm{s}$ on behalf of super heavy oil. The transient method was employed to calculated threshold pressure gradients of different heavy oils in different permeable porous media.

\subsection{Experimental Results}

The threshold pressure gradients of the three heavy oils at different temperature were shown from Fig. (5) to Fig. (7). The threshold pressure gradient of ordinary heavy oil with low viscosity gradually decreased as temperature increased in the same permeability of sand-pack as shown in Fig. (5). When temperature increased to a certain value what was called 'inflection temperature', the threshold pressure gradient became zero. At the same temperature, the threshold pressure gradient gradually decreased as permeability increased resulting from seepage resistance reduction in porous media. The results presented that the threshold pressure gradient became zero when it was at $68^{\circ} \mathrm{C}$ in sandpack of $1600 \times 10^{-3} \mu^{2}$, at $65^{\circ} \mathrm{C}$ in sand-pack of $2500 \times 10^{-3}$ $\mu \mathrm{m}^{2}$, and at $60^{\circ} \mathrm{C}$ in sand-pack of $6730 \times 10^{-3} \mu \mathrm{m}^{2}$.

The curves about threshold pressure gradient of ordinary heavy oil of $6110 \mathrm{mPa} \cdot \mathrm{s}$ at different temperature were shown in Fig. (6). The threshold pressure was only $216.6 \mathrm{kPa}$ at 30 ${ }^{\circ} \mathrm{C}$ in sand-pack of $6730 \times 10^{-3} \mu^{2}$. But the threshold pressure was over $610.0 \mathrm{kPa}$ in sand-pack of $1600 \times 10^{-3} \mu \mathrm{m}^{2}$. However, threshold pressure gradient largely decreased as temperature increased. When it was at $60{ }^{\circ} \mathrm{C}$, threshold pressure gradient became to be zero in higher permeable porous media. But the threshold pressure gradient gradually disappeared when it was only higher than $70{ }^{\circ} \mathrm{C}$ in lower permeable sand-pack of $1600 \times 10^{-3} \mu \mathrm{m}^{2}$.

Fig. (7) presented the relationships between threshold pressure gradient and temperature for super heavy oil of $10715 \mathrm{mPa} \cdot \mathrm{s}$ in different permeable porous media. The threshold pressure was $538.7 \mathrm{kPa}$, which was far more than ordinary heavy oil, in higher permeable sand-pack of $6730 \times 10^{-3} \mu^{2}$ at $30^{\circ} \mathrm{C}$. The value was even over $960 \mathrm{kPa}$ for super heavy oil in lower permeable sand-pack. Therefore, the seepage resistance of super heavy oil was larger than lower viscosity heavy oil in porous media. But threshold pressure gradient quickly decreased as temperature increased in porous media. When it was over $70{ }^{\circ} \mathrm{C}$, threshold pressure gradient gradually disappeared for super heavy oil in higher permeable sand-pack, that is, its inflection temperature was about $70{ }^{\circ} \mathrm{C}$. But when temperature was close to $80{ }^{\circ} \mathrm{C}$, threshold pressure gradient became to be zero in middle

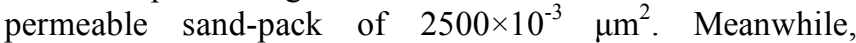
threshold pressure gradient gradually tended to be zero when it was over $85^{\circ} \mathrm{C}$ in lower permeable sand-pack of $1600 \times 10^{-}$ ${ }^{3} \mu \mathrm{m}^{2}$. Therefore, super heavy oil presented strongly nonNewtonian characteristics at reservoir temperature. This kind of heavy oil hardly was driven when it was far lower than inflection temperature.

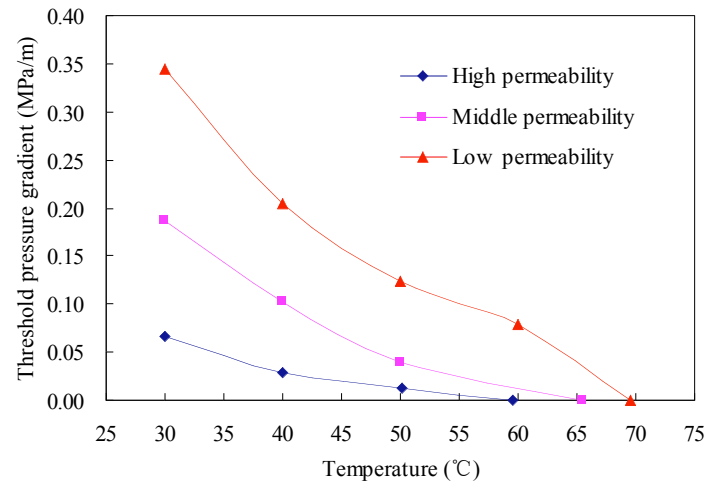

Fig. (5). Threshold pressure gradient vs. temperature of low viscosity of ordinary heavy oil.

\subsection{Inflection Temperature}

We established the relationships between inflection temperature and heavy-oil viscosity at $50{ }^{\circ} \mathrm{C}$ in different permeability, such as $6.73 \mu \mathrm{m}^{2}, 2.55 \mu \mathrm{m}^{2}$ and $1.60 \mu \mathrm{m}^{2}$ as shown in Fig. (8). The results showed that: 
(1) Inflection temperature tended to exponentially increase with viscosity of heavy oil in the same permeable porous media.

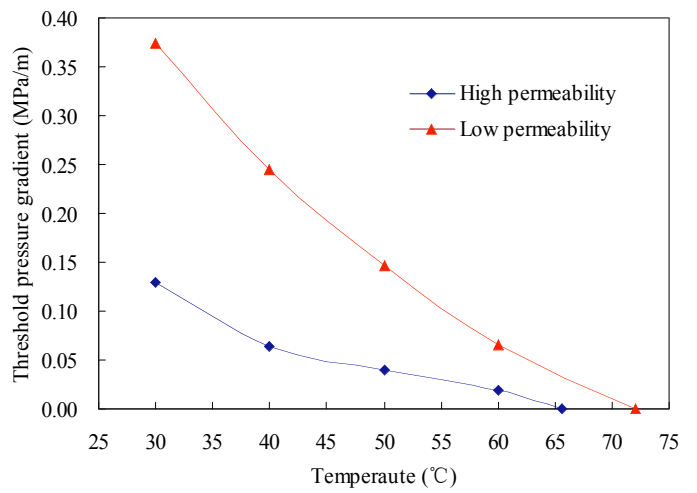

Fig. (6). Threshold pressure gradient vs. temperature of middle viscosity of ordinary heavy oil.

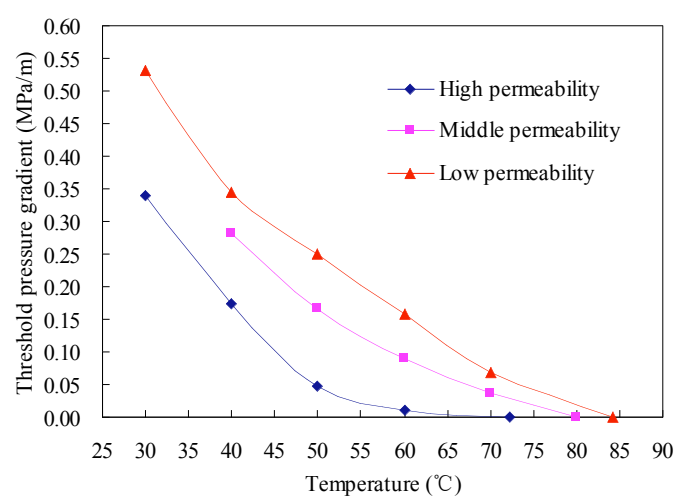

Fig. (7). Threshold pressure gradient vs. temperature of super heavy oil.

(2) Inflection temperature tended to largely decrease as permeability increased for the same oil sample.

The relationships between inflection temperature and viscosity of heavy oil at $50{ }^{\circ} \mathrm{C}$ could be expressed by the following equation:

$T_{c}=[27.670-8.224 \operatorname{Ln}(K)] \mu_{\mathrm{o5} 0}^{0.159}$

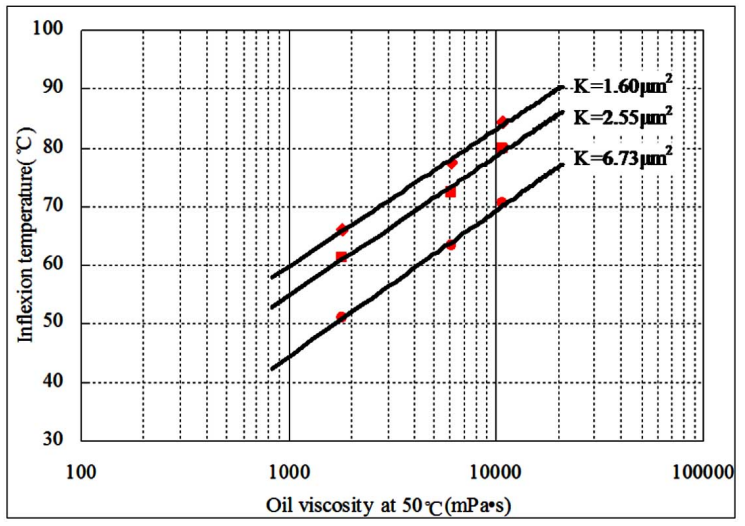

Fig. (8). The fitting curves of inflection temperature and viscosity of heavy oil at $50{ }^{\circ} \mathrm{C}$.

\section{CONCLUSIONS}

According to flow characteristics of heavy oil and material balance theory in porous media, an unsteady one dimension seepage numerical model of heavy oil in porous media was established, which considered threshold pressure gradient of heavy oil during migration. Basis on the theoretical analysis, a new transient experiment method was presented to measure threshold pressure gradient of heavy oil in porous media. This method need not consider flow-rate influence on experimental results, so the transient method was more accurate and need shorter test time than steady state method.

The experimental results show that, on the one hand heavy-oil migration in porous media was influenced by petroleum composition; on the other hand, it was influenced by pore structure of porous media. Inflection temperature of heavy oil presented exponentially increase as viscosity of heavy oil increased in the same permeable porous media.

\section{ACKNOWLEDGEMENTS}

The study was subsidized by National Natural Science Foundation of China (51104165) and the Research Fund for the Doctoral Program of Higher Education (20110007120003).

\section{CONFLICT OF INTEREST}

None declared.

\section{LIST OF SYMBOLS}

$v$

K

$\mu_{\mathrm{o}}$

$p$

$\lambda$

$\rho_{\mathrm{o}}$

$\phi$

$t$

$x$

$c_{\mathrm{o}}$

$\rho_{\text {osc }}$

$p_{\mathrm{sc}}$

$p_{\mathrm{i}}$

$P_{\mathrm{D}}$

$X_{\mathrm{D}}$

$t_{\mathrm{D}}$

$\lambda_{\mathrm{D}}$

$T$

$T_{\mathrm{c}}$

$\mu_{050}$
$=$ Seepage velocity of heavy oil, $\mathrm{m} / \mathrm{s}$

$=$ Absolute permeability of porous media, $\mu \mathrm{m}^{2}$

$=$ Viscosity of heavy oil, $\mathrm{mPa} \cdot \mathrm{s}$

$=$ Pressure, $\mathrm{Pa}$

$=$ Threshold pressure gradient of heavy oil, $\mathrm{Pa} / \mathrm{m}$

$=$ Density of heavy oil under $p, \mathrm{~kg} / \mathrm{m}^{3}$

$=$ Porosity of porous media, dimensionless

$=$ Time, $\mathrm{s}$

$=$ Distance, $\mathrm{m}$

= Isothermal compressibility of heavy oil, $\mathrm{Pa}^{-1}$

$=$ Density of heavy oil at standard condition, $\mathrm{kg} / \mathrm{m}^{3}$

$=$ Standard condition pressure, $\mathrm{Pa}$

$=$ Initial pressure in porous media, $\mathrm{Pa}$

$=$ Dimensionless pressure

$=$ Dimensionless distance

$=$ Dimensionless time

$=$ Dimensionless threshold pressure gradient

$=$ Temperature, ${ }^{\circ} \mathrm{C}$

$=$ Inflection temperature, ${ }^{\circ} \mathrm{C}$

$=$ Viscosity of heavy oil at $50^{\circ} \mathrm{C}, \mathrm{mPa} \cdot \mathrm{s}$

\section{REFERENCES}

[1] J.Y. Hu, S.B. Xu, and K.M. Cheng, "Geological and Geochemical Studies of Heavy Oil Reservoirs in China", Chinese J. Geochem., vol. 8, pp. 331-344, 1989. 
[2] J.Y. Niu, and J.Y. Hu, "Formation and distribution of heavy oil and tar sands in China", Mar. Petrol. Geol., vol. 16, pp. 85-95, 1999.

[3] J.H. Frances, "Heavy Oil and Oil (Tar) Sands in North America: An Overview \& Summary of Contributions", Nat. Resour. Res., vol. 15 , pp. 67-84, 2006.

[4] P. Hamid, and R. Islam, "Laboratory simulation of geochemical changes of heavy crude oils during thermal oil recovery", J. Petrol. Sci. Eng., vol. 12, pp. 219-231, 1995.

[5] W.H. Shadi, T.G. Mamdouh, and E. Nabil, "Heavy crude oil viscosity reduction and rheology for pipeline transportation", Fuel, vol. 89, pp. 1095-1100, 2010.

[6] M. Rafael, L. M. María, Z. Beatriz, M. Elizabeth, B. César, C.C. Juan, and A. Jorge, "Transportation of heavy and extra-heavy crude oil by pipeline: A review", J. Petrol. Sci. Eng., vol. 75, pp. 274282, 2011.

[7] H.F. Fan, Y.J. Liu, L.Y. Zhang, and X.F. Zhao, "The study on composition changes of heavy oils during steam stimulation processes", Fuel, vol. 81, pp. 1733-1738, 2002.

[8] A S. Magomadov, "Viscosity and Thermal Conductivity of Heavy Oils in the Region of High Temperatures and Pressures", High Temperature, vol. 42, pp. 238-241, 2004.

[9] J.M. Maria, M. Francisco, P. Pedro, and G. Crispulo, "Influence of pressure and temperature on the flow behaviour of heavy fuel oils", Rheol Acta, vol. 45, pp. 357-365, 2006.

[10] S.S. Behnam, R. Fariborz, and B. Tayfun, "Temperature effects on the heavy oil/water relative permeabilities of carbonate rocks", $J$. Petrol. Sci. Eng., vol. 59, pp. 27-42, 2007.

[11] P. Luo, and Y.G. Gu, "Effects of asphaltene content on the heavy oil viscosity at different temperatures", Fuel, vol. 86, pp. 1069 $1078,2007$.

[12] M.M. Barbooti, S.H. AI-Madfai, and D.A. Al-Sammerrai, "Thermogravimetric characterization of Quayarah heavy crude oils", J. Thermal Anal., vol. 31, pp. 253-260, 1986.
[13] R.R. Mohammad, and A.A. Taher, "Physical properties of heavy petroleum fractions and crude oils", Fluid Phase Equilib., vol. 117, pp. 217-224, 1996.

[14] P. Luo, C.D. Yang, and Y.G. Gu, "Enhanced solvent dissolution into in-situ upgraded heavy oil under different pressures", Fluid Phase Equilib., vol. 252, pp. 143-151, 2007.

[15] S. Anupras, and K. Regina, "Behaviour of a heavy fuel oil droplet on a hot surface", Int. J. Heat Mass Trans., vol. 49, pp. 1050-1057, 2006.

[16] S.H.J. Wang, Y.Z.H. Huang, and C. Faruk, "Experimental and theoretical investigation of the Zaoyuan field heavy oil flow through porous media", J. Petrol. Sci. Eng., vol. 50, pp. 83-101, 2006.

[17] I. Bondino, S.R. McDougall, and G. Hamon, "A pore-scale modelling approach to the interpretation of heavy oil pressure depletion experiments", J. Petrol. Sci. Eng., vol. 65, pp. 14-22, 2009.

[18] L. K. Thomas, D.L. Katz, and M.R. Tek, "Threshold Pressure Phenomena in Porous Media", SPE1816-PA, vol. 8, pp. 174-184, 1968.

[19] V.V. Skopetskii, V.S. Deineka, L.I. Sklepovaya, and T.P. Savosh, "Calculating unsteady seepage in a pressure gradient in the presence of thin weakly permeable inclusions", J Math Sci., vol. 72, pp. 2992-2997, 1994.

[20] G. Kaptay, and T. Barczy, "On the asymmetrical dependence of the threshold pressure of infiltration on the wettability of the porous solid by the infiltrating liquid", J. Mater. Sci., vol. 40, pp. 25312535, 2005.

[21] F.Q. Song, C.Q. Liu, and F.H. Li, "Transient pressure of percolation through one dimension porous media with threshold pressure gradient", Appl. Math. Mech., vol. 20, pp. 27-35, 1999.

(C) Pang and Liu; Licensee Bentham Open.

This is an open access article licensed under the terms of the Creative Commons Attribution Non-Commercial License (http://creativecommons.org/licenses/by-nc/3.0/) which permits unrestricted, non-commercial use, distribution and reproduction in any medium, provided the work is properly cited. 